\title{
Increasing the reliability of thermal energy transportation systemstaking into account forecasting the properties of thermal insulation during operation
}

\author{
Elvira Bazukova ${ }^{1, *}$, Yuri Vankov ${ }^{1}$ \\ ${ }^{1}$ Kazan Power Engineering University, 420066, 51, Krasnoselskaya st., Kazan, Russia
}

\begin{abstract}
The work is devoted to solving the problem of increasing the operational reliability of industrial thermal insulation, taking into account the prediction of changes in its properties during operation. A series of experiments was carried out with samples of mineral wool insulation made of basalt fiber of different density. The dependence of thermal conductivity $\lambda$ of basalt fiber insulation on density and temperature in the range from 50 to $350{ }^{\circ} \mathrm{C}$ is presented.
\end{abstract}

\section{Introduction}

By order of the Government of the Russian Federation dated 09.06.2020, the "Energy Strategy of the Russian Federation for the Period up to 2035 " was approved. One of its directions is to increase the reliability and efficiency of the heating network complex [1].

The structure of energy technology complexes can be divided into three main parts:

source - a set of industrial units and technological processes that pro-duce energy;

systems of transport and distribution of energy resources;

consumers of energy resources (industrial enterprises).

The efficiency of using fuel and energy resources depends on the effective interaction of each of the listed parts.

Power engineering complexes, where hightemperature coolants are used in large volumes, have a high potential for energy saving.

According to experts [2-4], heat losses through the insulated surfaces of existing industrial structures, equipment and pipelines is 356 million Gcal / year, or 65 million tons of fuel equivalent per year; through insulation of heat pipelines of heating networks - 324 million Gcal/year, or 59.5 million tons of fuel equivalent per year.

For thermal insulation of systems transporting hightemperature coo-lants, industrial thermal insulation is used, the overwhelming part $(85-90 \%)$ of which is mounted from fibrous materials (mineral wool and fiberglass products) [5].

Industrial thermal insulation has a wide operating temperature range, which ranges from -180 to $600^{\circ} \mathrm{C}$.

The temperature regime of operation of industrial thermal insulation, intense heat-humidity and mechanical effects of the environment have a significant impact on the decrease in the heat-shielding properties of the thermal-insulating material during operation.

For example, studies were carried out [6], as a result of which it was found that during the operation of a steam pipeline transporting steam with a temperature of $315^{\circ} \mathrm{C}$, the coefficient of thermal conductivity of the thermal insulation layer adjacent to the high-temperature zone increased by 1.5- 2 times.

A decrease in the heat-shielding properties of thermal-insulating mate-rials during operation determines their durability.

Ignoring the listed factors during choosing thermal insulation materials and designing thermal insulation leads to premature degradation of the properties of thermal insulating materials, disruption of the performance of the entire coolant transportation system, which leads to excess thermal losses.

Excessive thermal losses through the isolated surface of industrial structures, equipment, pipelines and heating networks reach 244 million Gcal, or 44 million tons of fuel equivalent per year [3].

To increase the operational reliability of systems transporting high-temperature coolants, it is necessary to consider how the heat-shielding properties of industrial thermal insulation will change, taking into account the features of its operation.

To determine the change in the thermophysical properties of thermal insulation during operation, laboratory studies were carried out in order to determine the change in the thermal conductivity of the thermal insulating material depending on the change in the temperature of the insulated surface (in the range from 50 to $400{ }^{\circ} \mathrm{C}$ ), as well as on the density of the thermal insulating material.

\section{Description of measurement equipment}

\footnotetext{
*Corresponding author: ell17@mail.ru
} 
The laboratory installation consists of a metal cylindrical pipe -1 , on top of which is a thermal-insulating material made of basalt fiber in the form of a hollow cylinder with a longitudinal cut -2 . The metal cylindrical pipe is a cartridge electric heater TCEH (steel pipe with a builtin inside heater). The power of the heater is $2500 \mathrm{~W}$, the operating temperature is up to $400{ }^{\circ} \mathrm{C}$. The pipe length is $500 \mathrm{~mm}$, the outer diameter is $32 \mathrm{~mm}$. Temperature control inside the pipe is carried out using a laboratory autotransformer -3 . To measure the temperature of the metal pipe, a chromel-alumel thermocouple mounted inside the TCEH was used (4). The signal from the sensors is read and converted using an analog-to-digital converter ADC (5).

To measure the temperature of the surface of the insulating material, we used chromel-alumel thermocouples ThCA (6), with an operating range of measured temperatures from $-200^{\circ} \mathrm{C}$ to $+1100^{\circ} \mathrm{C}$.

To measure the heat flux density, high-temperature heat flux sensors (HFS) (7) with the following characteristics were installed on the surface of the insulating material under study: size - 52x10 mm; thickness - $2 \mathrm{~mm}$; measurement range 10 $1000 \mathrm{~W} / \mathrm{m}^{2}$; time constant - no more than $10 \mathrm{~s}$; effective thermal conductivity coefficient $0.5 \mathrm{~W} /(\mathrm{m} \cdot \mathrm{K})$; thickness $-2 \mathrm{~mm}$.

Heat flux sensors and thermocouples are installed in the middle part of the pipe around the perimeter of the test sample at 3, 6, 9 and 12 hours (see Fig. 1).

The heat flux sensors were calibrated with conductive heat supply.
Measurements and processing of experimental data were carried out on equipment and software from National Instruments. To register signals from heat flux sensors, a modular SCXI 1102 signal conditioning system was used. The SCXI system includes an industrial chassis with matching modules installed in it. Analog input modules serve as an interface for sensors and signals and increase the quality and reliability of measurements by means of high-performance, low-noise matching circuits: amplification, isolation, multiplexing, filtering, sensor power supply, signal sampling and storage devices and switching of signals. Signals are connected to modules via removable screw connectors, $\mathrm{BNC}$ connectors or thermocouple plugs.
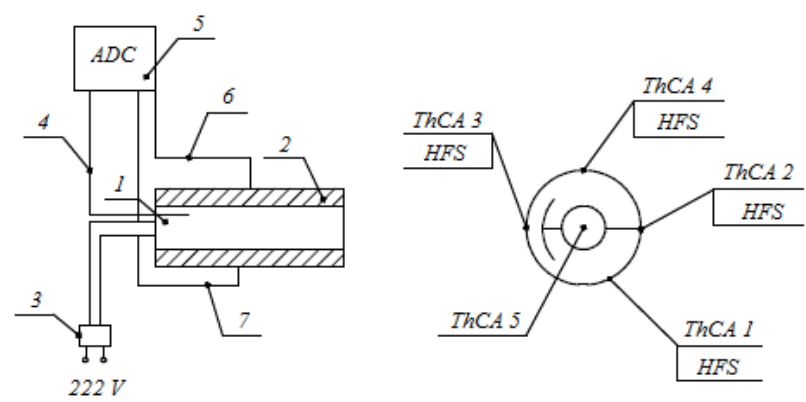

Fig. 1. Installation scheme for determining the thermal conductivity of a thermal-insulating material.

Table 1. Values of the coefficient of thermal conductivity $\lambda$ of a thermal-insulating material made of basalt fiber, depending on the density of the material and the temperature of the insulated surface.

\begin{tabular}{|c|c|c|c|c|c|c|c|c|c|}
\hline & \multicolumn{3}{|c|}{ sample 1 } & \multicolumn{3}{c|}{ sample 2 } & \multicolumn{3}{c|}{ sample 3 } \\
\hline $\begin{array}{c}\text { Temperature } \\
\text { of insulated } \\
\text { surface, }{ }^{\circ} \mathrm{C}\end{array}$ & $\begin{array}{c}80, \\
\mathrm{~kg} / \mathrm{m}^{3}\end{array}$ & $\begin{array}{c}100, \\
\mathrm{~kg} / \mathrm{m}^{3}\end{array}$ & $\begin{array}{c}120, \\
\mathrm{~kg} / \mathrm{m}^{3}\end{array}$ & $\begin{array}{c}80, \\
\mathrm{~kg} / \mathrm{m}^{3}\end{array}$ & $\begin{array}{c}100, \\
\mathrm{~kg} / \mathrm{m}^{3}\end{array}$ & $\begin{array}{c}120, \\
\mathrm{~kg} / \mathrm{m}^{3}\end{array}$ & $\begin{array}{c}80, \\
\mathrm{~kg} / \mathrm{m}^{3}\end{array}$ & $\begin{array}{c}100, \\
\mathrm{~kg} / \mathrm{m}^{3}\end{array}$ & $\begin{array}{c}120, \\
\mathrm{~kg} / \mathrm{m}^{3}\end{array}$ \\
\hline 50 & 0,0330 & 0,0206 & 0,0226 & 0,0213 & 0,0206 & 0,0177 & 0,0242 & 0,0217 & 0,0209 \\
\hline 100 & 0,0277 & 0,0254 & 0,0258 & 0,0258 & 0,0258 & 0,0240 & 0,0277 & 0,0263 & 0,0246 \\
\hline 150 & 0,0307 & 0,0295 & 0,0287 & 0,0313 & 0,0300 & 0,0279 & 0,0319 & 0,0298 & 0,0288 \\
\hline 200 & 0,0345 & 0,0334 & 0,0333 & 0,0365 & 0,0339 & 0,0315 & 0,0374 & 0,0345 & 0,0329 \\
\hline 250 & 0,0396 & 0,0374 & 0,0374 & 0,0417 & 0,0379 & 0,0359 & 0,0424 & 0,0394 & 0,0361 \\
\hline 300 & 0,0442 & 0,0428 & 0,0429 & 0,0490 & 0,0452 & 0,0403 & 0,0488 & 0,0460 & 0,0407 \\
\hline 350 & 0,0522 & 0,0499 & 0,0493 & 0,0573 & 0,0516 & 0,0457 & 0,0569 & 0,0526 & 0,0464 \\
\hline
\end{tabular}

\section{Research methodology}

The density of a constant unidirectional heat flux passing through the sample was determined by the additional wall method.

During testing, measurements were carried out with the placement of heat flux sensors shown in Fig. 1.

The heat flux density $q$ was determined after the establishment of a stationary thermal regime in the measurement zone.
With a known heat flux density, the thermal conductivity coefficient of the material under study was determined from the Fourier law formula:

$$
\lambda=\frac{q}{\left(T_{1}-T_{2}\right)} \cdot \delta
$$

where $q$ is the heat flux density, $\mathrm{W} / \mathrm{m}^{2} ; \delta$ - thickness of the investigated sample of thermal insulation, $\mathrm{m}$; $\left(T_{1}-T_{2}\right)$ - temperature difference between the faces of the test specimen, ${ }^{\circ} \mathrm{C}$. 
A series of experiments was carried out, during which the temperature on the outer surface of the metal pipe was maintained at 50, 100, 150, 200, 250, 300, $350{ }^{\circ} \mathrm{C}$.

Samples of thermal insulation from basalt fiber with a density of $80,100,120 \mathrm{~kg} / \mathrm{m}^{3}$ were studied. The thickness of the studied samples is $17 \mathrm{~mm}$, the length is $500 \mathrm{~mm}$.

Fig. 2 shows the dependence of the thermal conductivity $\lambda$ of a thermal-insulating material made of basalt fiber on the density and temperature.

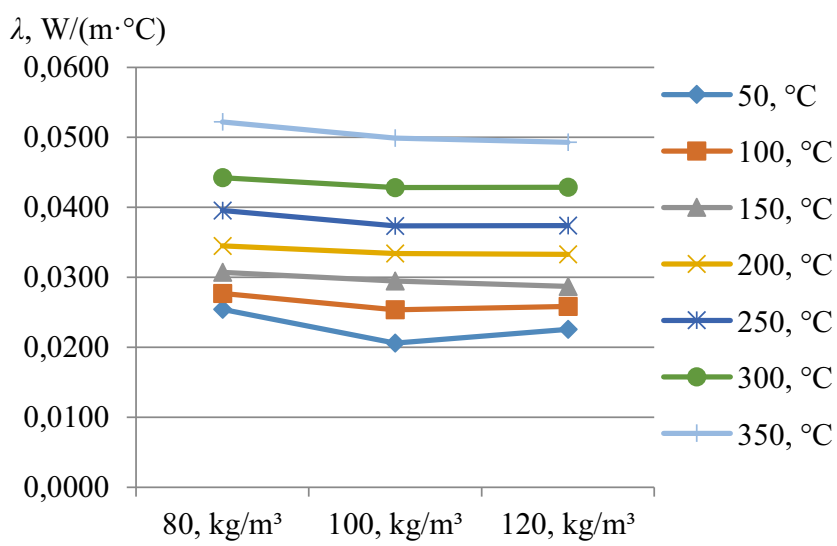

a)

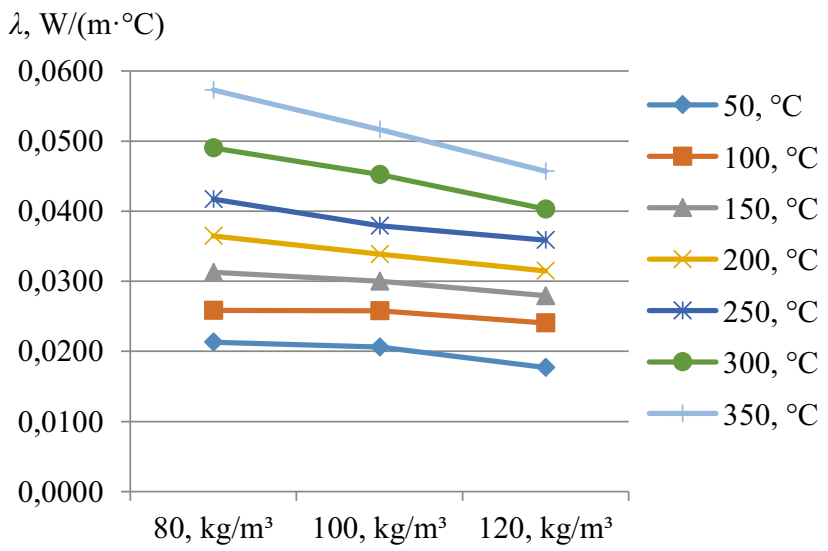

b)

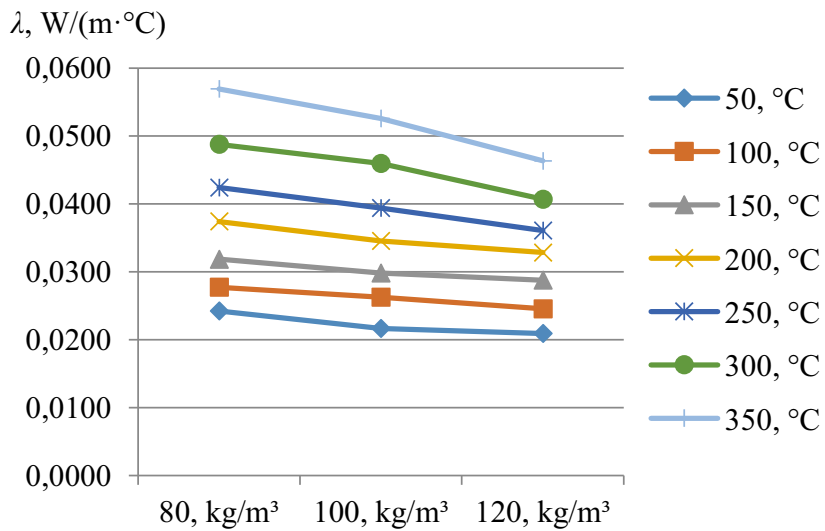

c)

Fig. 2. Dependences of thermal conductivity $\lambda$ of a thermalinsulating material made of basalt fiber on density and temperature: a) sample 1; b) sample 2; c) sample 3 .
The obtained values of the thermal conductivity coefficient $\lambda$ of a thermal-insulating material made of basalt fiber, depending on the density of the material and the temperature of the insulated surface, are presented in the table 1 .

From the results obtained it follows:

the temperature dependence of the thermal conductivity of basalt fiber mineral wool products is almost linear;

the thermal conductivity coefficient of mineral wool products made from basalt fiber increases with an increase in the temperature of the insulated surface;

the maximum difference between the values of the thermal conductivity coefficient $\lambda$ of the thermalinsulating material made of basalt fiber, depending on the density of the insulating material $(80,100,120 \mathrm{~kg} /$ $\mathrm{m}^{3}$ ), was $13.5 \%$.

\section{Conclusion}

Equations should be centred and should be numbered with the number on the right-hand side.

The operational reliability and durability of thermal insulation largely determine the conditions in which the thermal insulating materials are used.

The experimental results show how the coefficient of thermal conductivity of mineral wool products made of basalt fiber will change depending on the operating temperature and the density of the material.

Taking these features into account in the design of thermal insulation will make it possible to choose thermal insulating materials with optimal properties that ensure the value of heat losses within the standard values, the stability of heat-shielding properties during operation, which will ensure the durability of thermal insulation and operational reliability of the thermal energy transportation system.

\section{References}

1. Order of the Government of the Russian Federation dated 09.06.2020 N 1523-r About the approval of the Energy Strategy of the Russian Federation for the period up to 2035 .

2. V.V. Guryev, V.S. Zholudov, V.G. Petrov-Denisov, Thermal insulation in industry. Theory and calculation (M.: Stroyizdat, 2003)

3. V.S. Zholudov, Improvement of heat-shielding properties of heat-insulating structures made of fibrous materials for industrial buildings (Cand. tech. sciences dis. Moscow, 2000)

4. O.V. Smorodova, Dynamics of heat-shielding properties of mineral wool thermal insulation over the operation time, Scientific and practical electronic journal Alley of science 9, 367-370 (2017)

5. Yu.L Bobrov., Ye.G. Ovcharenko, B.M. Shoikhet, Ye.Yu. Petukhova, Thermal insulating materials and structures (M .: Infra-M, 2003) 
6. Yu.V. Vankov, E.R. Bazukova, N.D. Yakimov, Ye.G. Sheshukov, N.D. Chichirova, Investigation of the thermal destruction of the thermal insulation of a steam pipeline, Proceedings of Academenergo 4, 98-108 (2019) 